Ssciendo Studia Anglica Posnaniensia 53 (2018): 25-43

doi: 10.2478/stap-2018-0002

\title{
PATTERNS OF PRONUNCIATION OF ENGLISH INTERDENTAL FRICATIVES BY SOME YORUBA SPEAKERS OF ENGLISH IN A NIGERIAN UNIVERSITY
}

\author{
EUNICE O. FAJOBI AND AKINMADE T. AKANDE*
}

Department of English, Obafemi Awolowo University, Ile-Ife

\begin{abstract}
This paper is an investigation of the pronunciation patterns of English interdental fricatives by some Yoruba speakers of English at Obafemi Awolowo University (OAU), Ile-Ife. This was with a view to finding out the extent to which gender, the level of education, and the position in words of the interdental fricatives (i.e., the (th) variable as in think, pathetic, and path on the one hand, and the (dh) variable as in then, father, and clothe on the other hand) could affect the realisations of these two fricatives, otherwise known as (th) and (dh) variables. Data eventually used for this study were drawn from the reading performance of thirty-three informants who were of Yoruba origin. The thirty-three informants comprised 20 male and 13 female subjects with different levels of education ranging from undergraduate to doctoral. Our findings indicated that the $(\mathrm{dh})$ variable was significantly affected by gender while the (th) variable was not. It was also demonstrated that while the (th) was significantly affected by the level of education of informants, the (dh) variable had no statistically significant association with the speakers' level of education. Finally, the results of the study revealed that the position in a word (whether initial, medial, or final) of each of the variables affected the realisations of the two variables significantly. It was therefore concluded that sociolinguistic variables such as gender and the level of education were capable of affecting the rendition of linguistic variables significantly.
\end{abstract}

Keywords: Pronunciation; inter-dental fricatives; Yoruba speakers of English; Nigerian English; phonology.

Akinmade T. Akande, Department of English, Faculty of Arts, Obafemi Awolowo University, Ile-Ife, Nigeria, e-mail: akinmakande@yahoo.com 


\section{Introduction}

Studies have shown that Nigerian English (NE), which is a vibrant variety within world Englishes, is highly heterogeneous. Its heterogeneity can be connected to different factors; the most important of which are first the apparent existence of diverse ethnic groups in Nigeria, which has a great influence on the kind of English people speak and, secondly, the level of education, which can also sometimes account for the variation that is often observed in NE. While other factors such as parental background and the kind of schools attended (whether private or public) are important and can affect both spoken and written English, many scholars have foregrounded the region of origin and the level of education as the major factors that have so far contributed to variation in NE (Awonusi 1986; Jowitt 1991; Udofot 2004). Bamgbose (1971) claims that it is possible to tell the part of a country a Nigerian came from simply by listening to their spoken English and this is due to the fact that "the accents of most speakers of NE [Nigerian English] differ depending on the region they belong to" (Akande 2008: 431). So, it is possible to refer to someone as using Hausa English, Igbo English, or Yoruba English, because these varieties are remarkably distinct from one another in pronunciation.

Though Nigeria was colonized by the British for several decades and so one would naturally expect this to be reflected in the English spoken in the country, the sociolinguistic milieu of Nigeria has demonstrated that Received Pronunciation (RP), which is the British spoken model, is unrealistic and socially unacceptable for many people in Nigeria (cf. Eka 2000; Josiah 2009, 2011). There are studies which have reported that RP is not only unrealistic but that English in Nigeria has been phonologically domesticated. Some of the features highlighted in these studies as being involved in the phonological domestication process are a reduced vowel system, a reduced intonation system, absence of glottalization in some contexts where it is obligatory in native English settings, the insertion of vowels, syllabic consonants insertion or avoidance, the substitution of alveolar fricatives for interdental fricatives, lack of distinction between lax and tense vowels, a preponderance of accented syllables and so on (cf. Awonusi 1986; Akande 2004; Udofot 2004). As a matter of fact, there are many distinctive features which set the spoken variety of English in Nigeria apart from RP (Josiah, Bodunde \& Robert 2012). Given this background, the present study is aimed at investigating the patterns of how selected lecturers and students at the Obafemi Awolowo University, Ile-Ife realise the interdental fricatives (voiced and voiceless) in their spoken English. 


\section{Varieties differentiation and variation within Nigerian English}

Although scholars have employed several approaches in the examination of spoken Nigerian English (SNE), all these approaches are targeted towards answering one question: In what ways is SNE different from other Englishes? And relevant to this question is providing and theorising factors that can account for the observable differences between SNE and other world Englishes. One of these approaches is the variationist approach which emphasizes the existence of different varieties of spoken English. A variationist work such as this cannot but make reference to the Labovian variationist model (Labov 1963, 1972, 1994, 2006). In these works, and in other works that make use of the variationist approach (cf. Trudgill 1974; Mesthrie 1997; Herat 2005;), scholars often examine how social variables such as age group, gender, ethnicity, social class, and the level of education can lead to systematic differences and variability in language use. Drawing insights from this approach, the differences between SNE and other native varieties of English are seen as features rather than errors (cf. Banjo 1971; Eka 2000; Udofot 2004, 2013). Although another approach for treating SNE is the contrastive approach, which considers 'deviant' spoken forms as errors rather than features (Aladeyomi \& Adetunde 2007), this present study relies heavily on the variationist approach for its theoretical framework.

As noted above, NE, and indeed any variety of English that functions in a multilingual setting, cannot afford the luxury of uniformity as such a variety of English is often subjected to interference from indigenous languages. In connection with this, Gut (2004: 815) observes:

\footnotetext{
There is no uniform accent of English spoken throughout Nigeria. In fact, the diversity of the different kinds of English in the country is so great that Nigerian English (NigE) is usually divided into several sub-varieties.
}

Gut (2004), while stressing the heterogeneous nature of NE, observes that some English consonants and vowels have different variants in NE depending on regions and ethnicity. She points out, for instance, that the voiceless interdental fricative $/ \theta$ / will be realised as $[\theta]$ or [s] by a Hausa speaker, whereas in educated Yoruba English it will be realised as $[\theta]$ or [t]. Similarly, according to her, while $/ \mathrm{v} /$ is realised as [v] or [b] in Hausa English, it is rendered as [v] or [f] in Yoruba English (Gut 2004: 822-823). In spite of its heterogeneity, NE is distinctive from other dialects of English such as British English, Canadian English, American English, or South African Black English in that it is characterized by a reduced vowel system, it is non-rhotic, it has no velar nasal and post-alveolar fricative, and, more importantly, it is characterized by spelling pronunciation (cf. Jibril 1982; Jowitt 1991; Gut 2004). 
Udofot (1997) uses a native speaker of British English as a control against some Nigerians in order to make a comparison between NE and British English. In this study, she identifies three varieties of NE based on how close or far they are to British English. Firstly, she identifies the Sophisticated variety (V3), which she claims is spoken by people with a university education and people who have undergone special speech training. This variety is systematically different from British English mainly in the area of accentuation and intonation. Another variety identified in that study is the Standard variety (V2), which is used by speakers with tertiary education and is different from $\mathrm{V} 3$ in its accentuation and intonation patterns. Variety 1 is the non-Standard variety, which has some prosodic differences from British English as well as from the V2 and V3. Udofot seems to be making some correlations here between the level of education of speakers and the varieties of English they use. This kind of correlation had earlier been made by Jowitt (1991), Brosnahan (1958), and Banjo (1979). Akande (2008: 432) has noted that "...this correlation is not a clear-cut one as there may sometimes be a mismatch between the level of education and proficiency in English" (cf. also Jibril 1982; Udofot 1997) and remarks further that "language variation is a complex phenomenon, especially in a multilingual, multicultural setting with diverse socio-religious and family backgrounds such as we have in Nigeria" (2008: 432).

Many scholars have examined its distinctiveness, especially at the phonetic and phonological levels, from different perspectives. Akande (2008) examines, as one of the objectives of the study, the realisation of ten variables which include the (th), (dh), (v), (er), and (u) in the spoken English of Nigerian graduates. The data for the phonological aspect of the work are elicited from three reading materials which contain the target variables the study is interested in. The reading materials which are read aloud by each of the participants are a word list, sentences, and a reading passage. The study revealed that the English of Nigerian graduates is characterized by $t h$ - and $d h$-stopping, $h$-dropping and $h$-insertion, lack of distinction between lax and tense vowels, and that fricatives (whether voiced or voiceless) are often realised as voiceless in word-final position. In a similar study, Faleye (2008) investigated the pronunciation problems of Primary School teachers of English in Ibadan. The 120 subjects used in the study were asked to read a prepared text of ten short sentences designed to elicit morphophonological challenges they often face in spoken English. The study shows that there are several instances of mispronunciations in the English of the respondents.

Soneye (2008) examined the awareness as well as the pronunciation of the $\mathrm{CH}$ digraph by twenty university teachers of English and the pedagogical implications such awareness has for second language learners of English. Soneye's study is an attempt to address "the lack of uniformity between the spelling and sounds of the $\mathrm{CH}$ digraph in context which often result in 'deviant' 
pronunciation after periods of embarrassing hesitations" (Soneye 2008: 10). The study proposes inter alia that (1) the attitudes and responses of ESL learners of English to sound-spelling related phenomena is a viable method that can be used to assess phonological variation and it should be encouraged, and (2) in view of the fact that English borrowed words are usually problematic to ESL learners, language policy makers and curriculum planners should formulate policies that can enhance English teaching (Soneye 2008: 19). In 2009, Akande carried out a study on the pronunciation problems of some Yoruba learners of English. Using fifty Yoruba-speaking undergraduates as the subjects for the study, the study indicates that Yoruba speakers of English have problems with the pronunciation of English fricatives, lax vowels, central vowels, and diphthongs. It was also discovered that they had a problem "with the pronunciation of certain silent letters in some English words such as letter 'b' in climb, debt, and lamb; letter 'd' in handkerchief and letter ' $\mathrm{t}$ ' in listen which are pronounced or often phonologically represented" (Akande 2009: 67).

Like in many of her earlier studies, Udofot (2013) identifies features (both segmental and non-segmental) that distinguish Nigerian English from other varieties of world Englishes. Some of the segmental features identified are the realisation of diphthongs as monophthongs, the realisation of the voiced interdental fricative as a voiced alveolar plosive, lack of distinction between the voiceless alveolar plosive and voiceless interdental fricative, both of which are realised as voiceless alveolar plosive in many cases. Udofot (2013: 71), summing up her findings in relation to segmental features, remarks "fewer vowels and consonants resulting from the approximations of some English segments to close equivalents of Nigerian languages' sounds" exist in NE. The non-segmental features include the preference for unidirectional intonation tones to bidirectional ones. In this present study, we investigate the articulation of the stable sociolinguistic variables (th) and (dh) of the English interdental fricative (e.g., Wagner 2008: 110-111) in the speech of selected NE speakers to show that not only do variants of these variables exist in NE, but that the variants are also affected by factors such as gender, level of education, and the position in a word (initial, medial, or final) of the variables.

\section{Methodology}

\subsection{Preamble}

The present study made use of a questionnaire which contains two sections: a written section requesting information about the informants' gender, educational attainment, occupation, and ethnic origin; and a second section containing the utterances that were read aloud by the informants and recorded, and from which 
the test items for this study were extracted (see Section 3.2 below). The first section of the questionnaire was administered on forty informants from Obafemi Awolowo University. The responses showed that out of these forty informants 33 were Yoruba, six were Igbo, while one was Urhobo. Although we were aware that the distributions of the informants across ethnic groups do not necessarily have to be equal, the lopsidedness in the figures above (i.e., 33; 6, 1) is so great that it may affect the results of the study. In spite of our efforts, we could not find informants of Hausa origin to interview and even some of the Igbo informants interviewed were born and bred in Yoruba land; this, we believe, may affect their reading performance. The uneven distribution of the subjects was due to many reasons. First of all, OAU is situated in the south-western part of Nigeria; and this is a region that is not only dominated by the Yoruba but has Yoruba as the major indigenous language. Apart from this, the fact that we are Yoruba gave us some easy accessibility to Yoruba-speaking informants. The issue of ethnicity and ethnic loyalty is very important in Nigeria. A Yoruba person will see another Yoruba person as his or her brother or sister even if they are not biologically related; the same applies to other ethnic groups. The concept of brotherhood and sisterhood in the context of Nigeria is not always motivated by being born of the same parents. This applies largely to most African countries though. What this implies is that accessibility to informants is easily gained through ethnic affinities. Lastly, our observation showed that the percentage of students and staff in OAU who are Yoruba is about $70 \%$. All these account for why the majority of our subjects are Yoruba. Similarly, 24 of the informants are male, while the rest (16) are female. This again reflects the social reality in OAU, where male students and staff outnumber their female counterparts. In view of the foregoing, we decided to administer the second section of the questionnaire (i.e., the section that contains reading materials) on only the thirty-three informants who are of Yoruba origin and who had earlier given their consent to participate in the study. The subjects are made up of two groups: university lecturers and students. While the latter are still on-going with their undergraduate and graduate studies, the former hold degrees ranging from Master to Doctor of Philosophy (PhD) (see Table 1). Altogether, there are twenty males and thirteen females and they are all Yoruba speakers of Nigerian English based at least on their accent and their ethnic origin. 
Table 1. Distribution of subjects by degrees

\begin{tabular}{l|c|c|c}
\hline \multirow{2}{*}{ Level of education } & Equivalent years of & \multicolumn{2}{|c}{ Informants } \\
\cline { 3 - 4 } & schooling & Male & Female \\
\hline PhD & (21 years) & 5 & 1 \\
\hline Master & (18 years) & 9 & 2 \\
\hline First Degree & (16 years) & 3 & - \\
\hline Undergraduate & (<16 years) & 3 & 10 \\
\hline \multicolumn{2}{l}{ Total } & 20 & 13 \\
\hline
\end{tabular}

"Years of schooling" per degree is based on the structural 6-3-3-4 system of education according to the Nigerian national policy on education, which translates into 6 years of primary education, 6 years of secondary schooling (i.e., three years of junior secondary school and three years of senior secondary school), and a minimum of 4 years of tertiary education depending on the discipline. But tertiary education may progress into other higher graduate studies leading to the award of Master's and doctoral $(\mathrm{PhD})$ degrees. It takes a minimum of about two years after the first degree to complete a Master's and another minimum of three years after the Master's to qualify for a doctoral degree.

\subsection{Elicitation procedure}

Data for this study were generated by asking the subjects to read aloud twentyfive well-constructed utterances containing fifteen (th) and ten (dh) variable words (i.e., twenty-five "th-containing" words) that were designed to investigate how the subjects can articulate the English voiceless and voiced interdental fricatives $/ \theta /$ and $/ \delta /$ when they occur in words simply as "th" in the initial, medial, and final positions of utterances as in think/Mathematics/Sabbath (for voiceless interdental fricative) and then/father/bathe (for voiced interdental fricative).

Speakers' outputs were recorded using a Sharp portable MiniDisc recorder, model MD-MT88H. This was later transferred onto a speech analyser, Audacity, where it was possible to break up the longer speech files of each speaker into smaller bits. The test items were later extracted from the informants' utterances by concentrating on the relevant acoustic properties of each word, especially because only some specific words in the informants' renditions were needed as data. This method provided an added advantage of being able to invite a third party judgment (of phonologists) wherever we disagreed on any speaker's output, or where we simply needed clarification. Before being recorded, speakers were given ample time to read through the test-utterances as many times as they wanted until they were sure they could read fluently like they would in natural speech. That way, we believe that the signals generated for the study are empirically representative of the speakers' natural speech. Thus, the results can be 
generalized to form a model of natural speech. Furthermore, the tokens generated were listened to, sorted, counted, and grouped together by variants with a view to describing the variations that occur in Nigerian English when speakers articulate the variables (th) and (dh) in sample words (see Section 4).

\subsection{Test items}

The test items sandwiched in 25 utterances consisted of fifteen (th)-variable words which are expected to be realised as voiceless interdental fricative $/ \theta /$, and ten (dh)-variable words similarly constructed to be realised as voiced interdental fricative $/ \circlearrowright /$. The items used for realizing $/ \theta /$ are think, thunder, theft, thirty, thick, healthy, enthusiasm, bathroom, filthy, path, growth, mouth, Sabbath, faith, strengthen; while those for realizing / $/$ are thou, them, mother, worthy, southern, father, breathe, bathe, clothe and bothering.

\section{Analysis}

The data analysed in this study consists of eight hundred and twenty-five tokens altogether, i.e., twenty-five (th) and (dh) variables spoken by thirty-three informants ( $33 \times 25=825$ tokens). Out of the twenty-five test items, there are fifteen (th) variables which are expected to be realised as $/ \theta /$, while the remaining ten $(\mathrm{dh})$ variables are constructed to be realised as / $\mathrm{d} /$ when pronounced the British English way. In other words, the data consists of $495 / \theta /$ tokens ( 15 words spoken by 33 informants) and $330 / \mathrm{d} /$ tokens (10 words spoken by 33 informants). The fifteen test items realizing the $/ \theta /$ tokens are five words each containing the (th) variable in the initial, medial, and final positions. Out of the ten (dh) variable items realizing the $/ \delta /$ tokens, two occur in the initial position of the test items, five in the medial, and three in word-final positions. In the analyses that follow we present the Nigerian English speakers' renditions of the test items, in consonance with our research questions which are:

1. Can gender affect the realisations of the (th) and the (dh) variables (i.e., the English voiceless and voiced interdental fricatives $/ \theta /$ and $/ ð /)$ in any significant way?

2. Can the levels of education of the subjects affect the realisations of the (th) and the $(\mathrm{dh})$ variables significantly?

3. To what extent can the position in a word influence the realisations of the (th) and (dh) variables? 


\subsection{Findings}

Presented in this section are the analyses in relation to the rendition of the two variables under study (i.e., the (th) and (dh) variables). The sections are divided into sub-sections as can be seen below.

\subsubsection{Overall interpretation of the (th) variable in Nigerian English}

Reports common to research on non-native varieties of spoken English have always tended towards a general conclusion that speakers prefer to use close substitutes of their native sounds for sounds in the target language (TL) that are not present in the phoneme inventory of their mother tongue (e.g., Cruz-Ferreira 1987). This notion recurs in the results of the data analysed in this present study. For instance, whereas our subjects could be safely identified as belonging to Banjo's (1979) variety 3, i.e., the educated speakers of Standard Nigerian English (cf. Table 1), our findings in Table 2 indicate that while up to eight variants are possible for pronouncing the (th) variable in NE, speakers seem to prefer to articulate the variable as $[\mathrm{t}]$ rather than $[\theta]$, while they often articulate the $(\mathrm{dh})$ variable (or $/ \delta /)$ as [d] rather than as [ð]; and occasionally each of these two variables can be realised as some other sounds, including [f] or [s] (see Table 2).

Table 2. General interpretation of (th) and (dh) variables in spoken Nigerian English

\begin{tabular}{l|c|c}
\hline $\begin{array}{l}\text { Variants of the }(\mathrm{th}) \text { and }(\mathrm{dh}) \\
\text { variables in NE }\end{array}$ & Total tokens produced & Percentage token \\
\hline$[\mathrm{t}]$ & 268 & 32.48 \\
\hline$[\mathrm{d}]$ & 160 & 19.39 \\
\hline$[\theta]$ & 249 & 30.18 \\
\hline$[$ ð] & 140 & 16.97 \\
\hline$[\mathrm{f}]$ & 4 & 0.48 \\
\hline$[\mathrm{s}]$ & 1 & 0.12 \\
\hline$*[\mathrm{dr}]$ & 1 & 0.12 \\
\hline Zero variant & 2 & 0.24 \\
\hline Total & 825 & 100 \\
\hline
\end{tabular}

Out of the total 825 tokens generated from the informants' rendition of the (th)words presented to them, 268 (i.e., $32.48 \%$; the highest frequency compared to the other variants) were realised as $[\mathrm{t}]$. That was followed, in decreasing order, by [ $\theta]$ (249 tokens), [d] (160 tokens), [ð] (140 tokens), [f] (4 tokens), zero variant ( 2 tokens), and a token each of *[dr] and [s]. A general conclusion that may be drawn at this stage is that most Nigerian English speakers will, first and foremost, 
rate both the (th) and (dh) variables as a voiceless alveolar plosive [t] in the subconscious before any other adjustment that may be necessitated by demands of positive learning outcomes; the type that may require the production as $[\theta]$ or [ð]. In what follows from here, we present our findings in accordance with the research questions proposed above.

\subsection{Research Question 1}

Can gender affect the realisations of the (th) and (dh) variables (i.e., the English voiceless and voiced interdental fricatives $/ \theta /$ and $/ \delta /$ ) in any significant way?

Table 3 illustrates the subjects' articulation of the (th) and (dh) variables meant to be realised as $[\theta]$ and [ð] respectively if pronounced the Received Pronunciation (RP) English way. The table reveals variants of the variables in the outputs of the informants by gender.

Table 3. Informants' rendition of the (th) and (dh) variables by gender

\begin{tabular}{|c|c|c|c|c|c|c|c|c|}
\hline \multirow{2}{*}{$\begin{array}{l}\text { Var- } \\
\text { iable }\end{array}$} & \multirow{2}{*}{$\begin{array}{l}\text { Variants } \\
\text { produced }\end{array}$} & \multicolumn{6}{|c|}{ Tokens per variant } & $\chi^{2}$ \\
\hline & & Male & $\%$ & Female & $\%$ & Total tokens & $\%$ & \multirow{8}{*}{$\begin{array}{c}\chi^{2}=9.680 \\
d f=5 \\
p=.085\end{array}$} \\
\hline \multirow{7}{*}{$\begin{array}{l}\text { (th) } \\
\text { [or } / \theta /]\end{array}$} & {$[\mathrm{t}]$} & 153 & 51.00 & 81 & 41.54 & 234 & 47.27 & \\
\hline & [d] & 14 & 4.67 & 11 & 5.64 & 25 & 5.05 & \\
\hline & {$[\theta]$} & 106 & 35.33 & 88 & 45.13 & 194 & 39.20 & \\
\hline & [ð] & 26 & 8.67 & 13 & 6.67 & 39 & 7.88 & \\
\hline & [f] & 1 & 0.33 & 0 & 0 & 1 & 0.20 & \\
\hline & zero & 0 & 0 & 2 & 1.02 & 2 & 0.40 & \\
\hline & Total & 300 & 100 & 195 & 100 & 495 & 100 & \\
\hline \multirow{8}{*}{$\begin{array}{l}(\mathrm{dh}) \\
{[\mathrm{or} / \mathrm{d} /]}\end{array}$} & {$[\mathrm{t}]$} & 27 & 13.50 & 7 & 5.38 & 34 & 10.30 & \multirow{8}{*}{$\begin{array}{c}\chi^{2}=17.313 \\
d f=6 \\
p=.008\end{array}$} \\
\hline & [d] & 81 & 40.50 & 54 & 41.54 & 135 & 40.91 & \\
\hline & {$[\theta]$} & 24 & 12.00 & 31 & 23.85 & 55 & 16.67 & \\
\hline & [ð] & 65 & 32.5 & 36 & 27.69 & 101 & 30.61 & \\
\hline & [f] & 3 & 1.50 & 0 & 0 & 3 & 0.91 & \\
\hline & {$[* \mathrm{dr}]$} & 0 & 0 & 1 & 0.77 & 1 & 0.30 & \\
\hline & [s] & 0 & 0 & 1 & 0.77 & 1 & 0.30 & \\
\hline & Total & 200 & 100 & 130 & 100 & 330 & 100 & \\
\hline
\end{tabular}

Results from Table 3 present the outcome of the cross tabulation of the (th) and (dh) variables by gender (male/female). The (th) variants cross tabulated with gender produced a $\chi^{2}$ value of $9.680(\mathrm{df}=5, \mathrm{p}=0.085)$, which is not significant, since the $p$-value of $\chi^{2}$ is greater than the 0.05 threshold. The implication of this result is that gender has no significant influence on the (th) variants. However, 
results emanating from the cross tabulation of the $(\mathrm{dh})$ variable by gender showed that gender has statistically a significant association with the variants of (dh), since the $\mathrm{p}$-value of the $\chi^{2}$ obtained (i.e., 0.008 ) at $\mathrm{df}=6$ is not up to 0.05 . Thus, while gender as a variable does not influence (th) significantly, it affects (dh) variants significantly.

For variable (th) in the top panel of the table, results show five variants of the sound in the production by the male informants, while there is a sixth zero variant in the renditions of the female informants. Irrespective of gender, the informants realised the (th) variable (the voiceless interdental fricative $/ \theta /$ ) not only as voiced and voiceless interdental fricatives $[\theta]$ and $[\chi]$, but also as other variants, which include the voiceless labio-dental fricative [f], the voiceless alveolar plosive [t], the voiced alveolar plosive [d], and as zero variant by two female informants. Collectively, Table 3 demonstrates that the frequency of occurrence in their rendition is highest for the voiceless alveolar plosive [t] $(47.27 \%)$, followed by

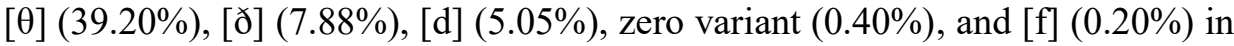
that order. When the subjects' renditions are compared by gender, however, the female subjects seem to express more preference for realising the variable as its principal variant $[\theta]$ than their male counterparts. For instance, whereas the females recorded their highest number of occurrences of the test item as [ $\theta]$ (45.13\% which is the highest percentage of their performance), the table illustrates that the males realised theirs mostly as $[\mathrm{t}](51 \%)$.

On the other hand, the bottom panel of Table 3 presents results of the informants' rendition of the (dh) variable. In addition to being similarly realised as some of the variants generated for the variable (th) such as $[\theta]$, [ð], [f], and [t], the $(\mathrm{dh})$ variable was realised as $*[\mathrm{dr}]$ and $[\mathrm{s}]$; each by two different female informants. However, there was no zero-variant in the variants realised for articulating the $(\mathrm{dh})$ variable. The $*[\mathrm{dr}]$ variant that was articulated by a female informant was realised in the final position of the word father in the data. The only plausible explanation for such behaviour is that the informant might be demonstrating some sort of American influence (e.g., rhoticization) on her rendition. But the fact that she is not consistent in her pronunciation of other words of similar sequence of characters in word-final positions (e.g., thunder and mother, which we regard as possibilities in spoken American English) makes that assumption somewhat untenable. Consequently, we regard that realisation of hers as one of the non-standard variants of the (dh) variable in NE. When compared by gender, the two groups seem to be behaving in a similar way in their realisation of the (dh) variable. As revealed in the bottom panel of Table 3 for instance, the two groups produced the highest frequency of [d] when compared to the other variants produced in the panel. Interestingly too, the next "preferred" variant to [d] for the two groups is [ð]; while they alternate between [ $\theta]$ and $[t]$ in their next preferences. Because of this performance, it is difficult to make a categorical 
statement in respect of gender when it comes to the (dh) variable. In other words, when it comes to articulating the (dh) variable, speakers are likely to pronounce $/ \delta /$ either as [d] or [ð] but the former may take precedence. These are likely to be followed by $[\theta]$ or $[t]$ for both of them. Very rarely too, $[\mathrm{f}]$ is a possibility for the male gender, while *[dr] and $[\mathrm{s}]$ are possible variants among the female gender only; but there does not seem to be a zero-variant for variable (dh) in NE.

\subsection{Research Question 2}

Can the levels of education of the subjects affect the realisations of the (th) and the $(\mathrm{dh})$ variables significantly?

\subsubsection{Rendition of the (th) variable by level of education}

Table 4 reveals the informants' performance in the test of how the (th) and the (dh) variables are realised based on their level of education. At a glance, the ToTVar (Total Token per Variant) column of the table illustrates that more speakers generally prefer to render the (th) variable as variants in the following order: $[t],[\theta],[\delta],[d]$, zero-variant or [f] (cf. Table 2). But when compared by their level of education, the table demonstrates that $\mathrm{PhD}$ holders articulate the variable as variants in the following order of preference: $[\theta],[t]$ and [ð]. There is a fourth very rare variant which is [d]; very rare because it constitutes only one token of the 90 tokens $(1.11 \%)$ of the (th) variable produced by the $\mathrm{PhD}$ informants in the study. Additionally, the table illustrates that [f] and zero-variants which are possibilities in the renditions by holders of other lower degrees in the data are absent in the tokens contributed by the $\mathrm{PhD}$ informants. This behaviour is suggestive of the fact that this group of informants might have been affected by the level of their educational attainment. At this level, beneficiaries are believed to have attained some level of competence in their educational pursuit.

Table 4. Rendition of the (th) and (dh) variables by educational levels

\begin{tabular}{|c|c|c|c|c|c|c|c|c|c|c|c|}
\hline \multirow[t]{2}{*}{$\begin{array}{l}\text { Var- } \\
\text { iable }\end{array}$} & \multirow[t]{2}{*}{$\begin{array}{l}\text { Variants } \\
\text { produced }\end{array}$} & \multicolumn{3}{|c|}{$\begin{array}{c}\text { Tokens produced } \\
\text { per variant }\end{array}$} & \multirow[b]{2}{*}{$\%$} & \multirow[b]{2}{*}{$\begin{array}{c}1^{\text {st }} \\
\text { Degree }\end{array}$} & \multirow[b]{2}{*}{$\%$} & \multirow[b]{2}{*}{ UG } & \multirow[b]{2}{*}{$\%$} & \multirow[b]{2}{*}{ ToTVar } & $\chi^{2}$ \\
\hline & & $\mathrm{PhD}$ & $\%$ & Master & & & & & & & \multirow{5}{*}{$\begin{array}{c}\chi^{2}= \\
36.891 \\
\mathrm{df}=15 \\
\mathrm{p}=.001\end{array}$} \\
\hline \multirow[t]{4}{*}{$\begin{array}{l}\text { (th) } \\
{[\mathrm{or} / \theta /]}\end{array}$} & {$[\mathrm{t}]$} & 37 & 41.11 & 96 & 58.18 & 22 & 48.89 & 79 & 40.51 & 234 & \\
\hline & [d] & 1 & 1.11 & 13 & 7.88 & 0 & 0 & 11 & 5.64 & 25 & \\
\hline & {$[\theta]$} & 38 & 42.22 & 46 & 27.88 & 19 & 42.22 & 91 & 46.67 & 194 & \\
\hline & [ð] & 14 & 15.56 & 9 & 5.45 & 4 & 8.89 & 12 & 6.15 & 39 & \\
\hline
\end{tabular}




\begin{tabular}{|c|c|c|c|c|c|c|c|c|c|c|c|}
\hline & {$[\mathrm{f}]$} & 0 & 0 & 1 & 0.61 & 0 & 0 & 0 & 0 & 1 & \\
\hline & Zero & 0 & 0 & 0 & 0 & 0 & 0 & 2 & 1.03 & 2 & \\
\hline & TOTAL & 90 & 100 & 165 & 100 & 45 & 100 & 195 & 100 & 495 & \\
\hline \multirow{8}{*}{$\begin{array}{l}(\mathrm{dh}) \\
{[\mathrm{or} / \mathrm{\partial} /]}\end{array}$} & {$[\mathrm{t}]$} & 6 & 10.00 & 13 & 11.82 & 6 & 20.00 & 9 & 6.92 & 34 & \multirow{8}{*}{$\begin{array}{c}\chi^{2}= \\
23.766 \\
\mathrm{df}=18 \\
\mathrm{p}=.163\end{array}$} \\
\hline & [d] & 16 & 26.67 & 52 & 47.27 & 14 & 46.67 & 53 & 40.77 & 135 & \\
\hline & {$[\theta]$} & 10 & 16.67 & 14 & 12.73 & 4 & 13.33 & 27 & 20.77 & 55 & \\
\hline & [ð] & 27 & 45.00 & 28 & 25.45 & 6 & 20.00 & 40 & 30.77 & 101 & \\
\hline & {$[\mathrm{f}]$} & 1 & 1.67 & 2 & 1.82 & 0 & 0 & 0 & 0 & 3 & \\
\hline & {$\left[{ }^{*} \mathrm{dr}\right]$} & 0 & 0 & 0 & 0 & 0 & 0 & 1 & 0.77 & 1 & \\
\hline & {$[\mathrm{s}]$} & 0 & 0 & 1 & 0.91 & 0 & 0 & 0 & 0 & 1 & \\
\hline & TOTAL & 60 & 100 & 110 & 100 & 30 & 100 & 130 & 100 & 330 & \\
\hline
\end{tabular}

As the table reveals, a total of 165 tokens of the (th) variable are produced by the Master's degree informants in this study. Out of these tokens, the analysis indicates that most speakers prefer to realise the variable as [t] (96 tokens) than as any other variant produced by the group, which are, in order of preference, $[\theta]$ (46 tokens), [d] (13 tokens), [ð] (9 tokens), and [f] (one token). First of all degree holder informants in this study produced a total of forty-five tokens of the test items for the (th) variable. As Table 4 demonstrates, only three variants are available for rendering the variable by this group. The variants are [t] (22 tokens), [ $\theta]$ (19 tokens), and [ð] (4 tokens). Next are the undergraduate subjects. Results in Table 4 reveal that undergraduates were able to articulate the (th) variable in five different ways which are $[\theta],[\mathrm{t}],[ð],[\mathrm{d}]$, and zero-variant. One hundred and ninety-five tokens are produced altogether by these informants for articulating the variable (th). Respectively, the tokens per the listed variants are $91[\theta], 79[\mathrm{t}], 12$ [ð], 11 [d], and 2 (zero-variants). An inference that may be drawn from this performance is that the (th) variable is more likely to be produced by the undergraduates as a voiceless interdental fricative $[\theta]$ than as any other variant. One reason may be because the undergraduates are still on-going with their studies and the subject-matter may still be fresh in their memories than it is for the other higher degree holders such as the holders of First and Master's Degrees.

In conclusion, the findings in this study showed that the level of education may affect the realisation of the (th) variable significantly. This is because when the rendition of the (th) variable was cross tabulated with data from educational levels (i.e., PhD, Master, First Degree, and Undergraduate), the cross tabulation showed a p-value of 0.001 which is less than the 0.05 significant level. The 
rendition of (th) variable as $[\theta]$ is evident in the productions by both the lowest (undergraduates) and the highest $(\mathrm{PhD})$ degree holders. This is unlike the $[\mathrm{t}]$ variant which ranks highest in the productions by the remaining two groups (Master's and First degree holders), which again is a reflection of the informants' collective behaviour in the entire data $(32.48 \%$; see Table 2$)$.

\subsubsection{Rendition of the $(\mathrm{dh})$ variable by level of education}

Table 4 presents the results of how the informants articulated the $(\mathrm{dh})$ variable in the data. The findings reveal that the NE speakers are able to produce the (dh) variable in seven different ways, which are $[\mathrm{t}],[\mathrm{d}],[\theta],[ð],[\mathrm{f}],{ }^{*}[\mathrm{dr}]$, and $[\mathrm{s}]$.

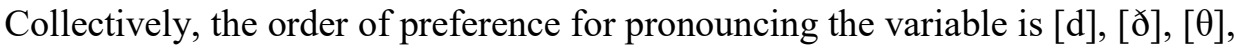
[t], [f], *[dr], and [s]; the last two being in no particular order. There is no statistical evidence that educational attainment indicates any significant effect on how the (dh) variable is articulated by the informants. This is so because the $\mathrm{p}$ value (which is 0.163 at $\mathrm{df}=18$ ), like other cases above, is greater than the 0.05 level of significance. Whereas the subjects collectively articulate $(\mathrm{dh})$ in most cases as [d] (i.e., $40.91 \%$ overall; cf. Table 3); results in Table 4 show that out of the 60 tokens of the (dh) variable test items produced by the informants who have attained a $\mathrm{PhD}, 27$ tokens (i.e., 45\%) come out as [ð], which is the principal variant. This is followed by 16 tokens of [d] (i.e., 26.67\%), 10 tokens of [ $\theta$ ] (i.e., $16.67 \%$ ), 6 tokens of [t] (i.e., 10\%), and only one token of [f] (i.e., 1.67\%). The variants $*[\mathrm{dr}]$ and $[\mathrm{s}]$, which are possible options in the renditions of the master's degree and undergraduate subjects, are not present in the tokens of (dh) produced by this group of speakers.

In the case of informants with a Master's degree, the results of their performance indicate that the $(\mathrm{dh})$ variable has a very high probability of being articulated as [d], followed by the principal variant [ð] and by others, which include $[\theta]$, [t], [f], and [s]. Altogether, these informants produced 110 tokens for the $(\mathrm{dh})$ variable. Out of these, 52 tokens $(47.27 \%)$ are realised as [d], while tokens for the remaining variants are $28(25.45 \%)$ for [ð], 14 (or 12.73\%) for [ $\theta$ ], $13(11.82 \%)$ for [t], $2(1.82 \%)$ for [f] and $1(0.91 \%)$ for [s]. No case of * [dr] was recorded by this group.

As revealed in the bottom panel of Table 4, results with regard to informants who hold a First degree illustrate that only four variants are available for pronouncing the $(\mathrm{dh})$ variable. In order of preference, these include [d], which occurred in $46.67 \%$ of the cases, $[t]$ and $[\delta]$ ( $20 \%$ respectively), and [ $\theta](13.33 \%)$. Variants [f], [s], and $*[\mathrm{dr}]$ are not present in the renditions by this group. Furthermore, five variants of the $(\mathrm{dh})$ variable, totalling 130 tokens, are produced by the undergraduate informants in this study. As the table indicates, the highest percentage of their production goes for [d] $(40.77 \%)$, while the other variants are 
$[ð](30.77 \%),[\theta](20.77 \%),[\mathrm{t}](6.92 \%)$, and the unexpected $*[\mathrm{dr}](0.77 \%)$. The variant $[\mathrm{s}]$ does not exist in the outputs by this group. In conclusion, the findings in Table 4 suggest that while the realisation of the variable (th) is affected significantly by the speakers' level of education, the variable (dh) is not affected in any significant way.

\subsection{Research Question 3}

To what extent can the position in a word influence the realisation of the (th) and (dh) variables?

\subsubsection{Position in the words having the (th) variable}

Table 5 indicates that, to a large extent, the position in words can affect the pronunciation of (th) and (dh) variables as presented below. In Table 5, the results demonstrate that when the (th) variable occurs in the initial position of words, only two variants $[t]$ and $[\theta]$ are realised by our informants. But when it occurs in the final position, there is an added variant [d] to what obtains in the initial position. The case is somewhat different when the (th) variable occurs in the medial position of words; as many as six variants ([t, d, $\theta, \partial, f]$ and zero-variant) are recorded. When considered together, however, it is crystal clear that the highest frequency of tokens realised for the pronunciation of the (th) variable alternates between $[\theta]$ and $[t]$, which are the only variants for its pronunciation in the initial position as mentioned already. This behaviour corroborates the findings by Labov (2006), cited in Wagner (2008: 114), in a similar study which he carried out on informants in New York City.

\subsubsection{Position in the words having the $(\mathrm{dh})$ variable}

According to Wagner (2008: 114), "alternation in (dh) is believed to have existed since the earliest history of English", with the two principal variants being [ð] (the voiced interdental fricative) and [d] (the voiced alveolar or dental stop or plosive). Other variants that have also been previously reported for this variable include affricates, marginal zero variants, and the voiced labiovelar fricative [v]. In what follows, we analyse the possible variants of the (th) and (dh) variables in Nigerian English, especially when they occur in the initial, medial, and final positions of words, to illustrate the influence of these positions on the pronunciation of the variables.

Like its voiceless counterpart, we can observe in Table 5 that (dh) is greatly influenced by position in words in Nigerian English. In the initial position, only two variants, both voiced, are possible: [d] (the voiced alveolar stop or plosive) and $[ð]$ (the voiced interdental fricative). The frequency of occurrence is higher, 
however, for [d] $(72.73 \%)$ when compared to [ð], which is just $27.27 \%$ of all the tokens in the initial position. Furthermore, five and six variants, respectively, are realised by our informants for articulating the (dh) variable in the medial and final positions. Variants in the medial position are $[t],[d],[\theta]$, $[ð]$, and *[dr] (which has no match in the British English sound system), while those in the final position are $[\mathrm{t}, \mathrm{d}, \theta, \partial, \mathrm{f}]$ and $[\mathrm{s}]$. The most preferred option for pronunciation in the medial position alternates between [d] $(49.09 \%)$ and [ð] $(45.45 \%)$ while the remaining three variants are almost negligible, especially the $[\theta]$ and $*[\mathrm{dr}]$ renditions, which are realised by an informant each. Out of the six variants produced in the final position for the $(\mathrm{dh})$ variable, preference seems to alternate between $[t](27.27 \%)$ and $[\theta](55.56 \%)$. The other remaining four variants, $[d, \delta, f]$ and $[s]$, are lower in frequency compared to $[\theta]$ and $[\mathrm{t}]$.

Table 5. Effects of the position in words on the realisations of the variables (th) and (dh)

\begin{tabular}{|c|c|c|c|c|c|c|c|c|}
\hline \multirow[t]{2}{*}{ Variable } & \multirow[t]{2}{*}{$\begin{array}{l}\text { Variants } \\
\text { produced }\end{array}$} & \multicolumn{6}{|c|}{$\begin{array}{l}\text { Tokens (and percentage) } \\
\text { per position of occurrence in words }\end{array}$} & \\
\hline & & Initial & $\%$ & Medial & $\%$ & Final & $\%$ & \\
\hline \multirow{7}{*}{ (th) $[\mathrm{or} / \theta /]$} & {$[\mathrm{t}]$} & 98 & 59.39 & 62 & 36.90 & 74 & 45.68 & \multirow{7}{*}{$\begin{array}{c}\chi^{2}= \\
152.725 \\
\mathrm{df}=10 \\
\mathrm{p}=.000\end{array}$} \\
\hline & [d] & 0 & 0 & 24 & 14.29 & 1 & 0.62 & \\
\hline & {$[\theta]$} & 67 & 40.61 & 40 & 23.81 & 87 & 53.70 & \\
\hline & [ð] & 0 & 0 & 39 & 23.21 & 0 & 0 & \\
\hline & {$[\mathrm{f}]$} & 0 & 0 & 1 & 0.60 & 0 & 0 & \\
\hline & Zero & 0 & 0 & 2 & 1.19 & 0 & 0 & \\
\hline & Total & 165 & 100 & 168 & 100 & 162 & 100 & \\
\hline \multirow[t]{8}{*}{ (dh)[or/ð/] } & {$[\mathrm{t}]$} & 0 & 0 & 7 & 4.24 & 27 & 27.27 & \multirow{8}{*}{$\begin{array}{c}\chi^{2} \\
=249.410 \\
\mathrm{df}=12 \\
\mathrm{p}=.000\end{array}$} \\
\hline & [d] & 48 & 72.73 & 81 & 49.09 & 6 & 6.06 & \\
\hline & {$[\theta]$} & 0 & 0 & 1 & 0.61 & 55 & 55.56 & \\
\hline & [ð] & 18 & 27.27 & 75 & 45.45 & 8 & 8.08 & \\
\hline & {$[\mathrm{f}]$} & 0 & 0 & 0 & 0 & 2 & 2.02 & \\
\hline & {$[\mathrm{dr}]$} & 0 & 0 & 1 & 0.61 & 0 & 0 & \\
\hline & {$[\mathrm{s}]$} & 0 & 0 & 0 & 0 & 1 & 1.01 & \\
\hline & Total & 66 & 100 & 165 & 100 & 99 & 100 & \\
\hline
\end{tabular}


The results in Table 5 show that there is a statistically significant relationship between position in words (i.e., initial, medial, and final) and the (th) variables (six categories from [t] to zero). This is the case as p-value is 0.000 obtained from the $3 \times 2$ table where position in words - initial, medial, and final - were cross tabulated with the realisations of the (th) variables is less than 0.05 significance level. This implies that the association that exists between positions in words (three strands) and realisations of the (th) variables (six categories) is significant. Similarly, data relating to informants' rendition of the $(\mathrm{dh})$ variables were crosstabulated with data on tokens per variant by positions of occurrences.

The results revealed that for each of the (th) and (dh) variables, there is a significant association between the positions of occurrence and each of the two variables. As can be seen from the table, the p-value for each of the two variables is 0.000 which is not up to the 0.05 level of significance. Table 5 also reveals that variants of the (th) variable are relatively lesser in number at both the initial and final positions than at the medial position. The case is different with the (dh) variable, where variants are few only at the word-initial position compared to the medial and final positions. A logical conclusion that may be drawn in respect of our research question in this section is that the position in a word of the variables (th) and (dh) exerts a statistically significant influence on their realisations.

\section{Conclusion}

In summary, the results in this study demonstrated that indeed, stable variables such as (th) and (dh) are sometimes significantly affected by sociolinguistic factors such as gender, level of education, as well as the context of operation. Our findings have indicated that gender significantly affected the (dh) variable just as the position of occurrence has a statistically significant association with the two variables, while the (th) variable was not significantly influenced by gender. Similarly, results showed that while the realisation of the variable (th) was affected significantly by the speakers' level of education, the variable (dh) was not so affected in any significant way. All of these sociolinguistic factors have been reported as factors that can be used to assess the similarities and differences that may exist between native and non-native speakers in the emerging variants when the effects of the independent variables on the stable are investigated (Labov 2006; Wagner 2008). Our study has also revealed further that affricates and the voiced labio-velar fricative that were reported as variants of the (dh) variable in New York English (e.g., Wagner 2008, citing Labov 2006) were not found in Nigerian English. 


\section{REFERENCES}

Akande, Akinmade T. 2004. The reinterpretation of the RP English monophthongs by Yoruba Speakers of English: An exploratory approach. M.A Research Report, The University of the Witwatersrand, Johannesburg.

Akande, Akinmade T. 2008. Investigating dialectal variation in the English of Nigerian university graduates: Methodology and pilot study. Studia Anglica Posnaniensia 44. 431-456.

Akande, Akinmade T. 2009. Some aspects of the pronunciation problems in the spoken English of some Nigerian undergraduates. Papers in English and Linguistics 10. 56-69.

Aladeyomi, S. A. \& A. K. Adetunde. 2007. Errors of segmental phonemes in the spoken English of Nigerian English newscasters. Medwell Journal: The Social Sciences 2(3). 302-306.

Awonusi, Victor O. 1986. Regional accents and internal variability in Nigerian English: A historical analysis. English Studies 67(6). 555-560. DOI: 10.1080/00138388608598483

Bamgbose, Ayo. 1971. The English language in Nigeria. In John W. Spencer (ed.), The English language in West Africa, 35-48. London: Longman.

Banjo, Ayo. 1971. Towards a definition of Standard Nigerian Spoken English. In M. Houis (ed.), Actes du $8^{e}$ Congress de la Société Linguistique de L'Afrique Occidental, 165-175. Abidjan: University of Abidjan.

Banjo, Ayo. 1979. Beyond intelligibility in Nigerian English. In Ebo Ubahakwe (ed.), Varieties and function of English in Nigeria, 7-13. Ibadan: African University Press.

Brosnahan, L. F. 1958. English in southern Nigeria. English Studies 39: 97-110. DOI: $10.1080 / 00138385808597010$

Cruz-Ferreira, Madalena. 1987. Non-native interpretive strategies for intonational meaning: An experimental study. In Allan James \& Jonathan Leather (eds.), Sound patterns in second language acquisition, 103-120. Dordrecht: Foris Publications.

Eka, David. 2000. Issues in Nigerian English usage. Uyo: Scholar Press Ltd.

Faleye, James. 2008. Morpho-phonological problems of primary school teachers of English in Ibadan. Ife Studies in English Language 7. 14-24.

Gut, Ulrike B. 2004. Nigerian English: Phonology. In Bernd Kortmann \& Edgar W. Schneider (eds.), A handbook of varieties of English, 813-830. New York: Mouton de Gruyter. DOI: $10.1515 / 9783110175325.1 .813$

Herat, Manel. 2005. BE variation in Sri Lankan English. Language Variation and Change 17(2). 181-208. DOI: 10.1017/S0954394505050088

Jibril, Mohammed. 1982. Phonological variation in Nigerian spoken English. Unpublished Ph.D dissertation, University of Lancaster.

Josiah, Ubong. 2009. A synchronic analysis of assimilatory processes in educated Nigerian spoken English. Unpublished Ph.D dissertation, University of Ilorin.

Josiah, Ubong. 2011. Aspiration in Nigerian English: Controversies and challenges. In Inyang Udofot \& Juliet Udoudom (eds.), English usage in Nigeria since 1842: Patterns and change. A festschrift for Prof. David Eka, 79-102. Uyo: Devconsort Services Ltd.

Josiah, Ubong, Helen Bodunde \& Esther Robert. 2012. Patterns of English pronunciation among Nigerian undergraduates: Challenges and prospects. International Journal of Business, Humanities and Technology 2(6). 109-117.

Jowitt, David. 1991. Nigerian English usage: An introduction. Ibadan: Longman.

Labov, William. 1963. The social motivation of a sound change. Word 19(3). 273-309. DOI: 10.1080/00437956.1963.11659799 
Labov, William. 1972. Sociolinguistic patterns. Philadelphia: University of Pennsylvania Press.

Labov, William. 1994. Principles of linguistic change. Oxford: Basil Blackwell.

Labov, William. 2006. The social stratification of English in New York City (2nd ed.). Cambridge: Cambridge University Press.

Mesthrie, Rajend. 1997. A sociolinguistic study of topicalisation phenomena in South African Black English. In Edgar W. Schneider (ed.), Englishes around the world: Studies in honour of Manfred Görlach. Vol. 2: Caribbean, Africa, Asia, Australasia, 119-140. Amsterdam: John Benjamins. DOI: 10.1075/veaw.g19.12mes

Soneye, Taiwo. 2008. CH digraph in English: Patterns and propositions for ESL pedagogy. Papers in English and Linguistics 9. 9-20.

Trudgill, Peter. 1974. The social differentiation of English in Norwich. Cambridge: Cambridge University Press.

Udofot, Inyang. 1997. The rhythm of spoken Nigerian English. Unpublished Ph.D dissertation, University of Uyo.

Udofot, Inyang. 2004. Varieties of spoken Nigerian English. In Segun Awonusi \& E. A. Babalola (eds.), The domestication of English in Nigeria: A festschrift for Abiodun Adetugbo at 65, 93-113. Lagos: University of Lagos Press.

Udofot, Inyang. 2013. Features of spoken Nigerian English. In Akinmade T. Akande \& Rotimi Taiwo (eds.), Contact linguistics in Africa and beyond, 61-74. New York: Nova Publishers.

Wagner, Suzanne E. 2008. Linguistic change and stabilization in the transition from adolescence to adulthood. Unpublished Ph.D. dissertation, University of Pennsylvania. https://msu.edu/ wagnersu/Papers/Wagner-2008-front.pdf 